International Journal of Automotive and Mechanical Engineering ISSN: 2229-8649 (Print); ISSN: 2180-1606 (Online);

Volume 14, Issue 3 pp. 4518-4530 September 2017

CUniversiti Malaysia Pahang Publishing

DOI: https://doi.org/10.15282/ijame.14.3.2017.10.0357

\title{
Investigation on TIG welding parameters of 2205 duplex stainless steel
}

\author{
M. Ravichandran, A. Naveen Sait* and U. Vignesh \\ Department of Mechanical Engineering, Chendhuran College of Engineering and \\ Technology, Pudukkottai-622 507, Tamil Nadu, India \\ *Corresponding author: naveensait@yahoo.co.in
}

\begin{abstract}
TIG welding process parameters were analysed for joining duplex stainless-steel plates. Signal to noise (SN) ratio and Analysis of Variance (ANOVA) analyses were applied for investigating the selected welding parameters. The selected parameters were current (A), gas flow rate $(\mathrm{L} / \mathrm{min})$ and speed $(\mathrm{mm} / \mathrm{min})$. The purpose of this work is to produce weld joints with maximum impact of strength and hardness. L9 orthogonal array was selected according to the aforementioned factors with three levels. The impact strength of the joints was found using the Izord impact testing machine and hardness of all joints was measured using the Brinell Hardness machine. From the $\mathrm{SN}$ ratio analysis, it was observed that for the high impact strength, the required welding current was $150 \mathrm{~A}$, gas flow rate was $14 \mathrm{~L} / \mathrm{min}$ and the welding speed was $210 \mathrm{~mm} / \mathrm{min}$ while for high hardness, the welding current was $190 \mathrm{~A}$, gas flow rate was $12 \mathrm{~L} / \mathrm{min}$ and the welding speed was $175 \mathrm{~mm} / \mathrm{min}$. ANOVA analysis indicated that the gas flow rate was the most significant one for both impact strength and hardness of the joints.
\end{abstract}

Keywords: TIG welding; duplex stainless steel; SN ratio analysis; ANOVA.

\section{INTRODUCTION}

There are different types of stainless steels; when nickel is added, the crystal structure makes such steels virtually non-magnetic and less brittle at low temperatures. For greater hardness and strength, more carbon is added. Duplex stainless steels have a mixed microstructure of austenite and ferrite, the aim usually being to produce a 50/50 mix, although in commercial alloys, the ratio may be $40 / 60[1,2]$. Duplex stainless steels have roughly twice the strength compared to austenitic stainless steels and also improved resistance to localised corrosion, particularly pitting, crevice corrosion and stress corrosion cracking. They are characterised by high chromium (19-32\%) and molybdenum (up to 5\%) and lower nickel contents than austenitic stainless steels. The properties of duplex stainless steels are achieved with the overall lower alloy content than similar-performing super-austenitic grades, making their use cost-effective for many applications [3-5]. Arc welding is a type of welding that uses a welding power supply to create an electric arc between an electrode and the base material to melt the metals at the welding point. Gas tungsten arc welding is also called as TIG welding [6-9]. Tungsten inert gas (TIG) welding is an arc welding process that produces coalescence of metals by heating them with an arc between a non-consumable electrode and the base metal. The TIG welding process is generally used for welding these alloys $[10,11]$. Tungsten inert gas welding which uses a non-consumable tungsten electrode and an inert gas for arc shielding is an extremely important arc welding process. It is commonly used for welding 
hard-to-weld metals such as stainless steel. In TIG welding, the electric arc is produced between a non-consumable tungsten electrode and the workpiece. There is an electrode holder in which the non-consumable tungsten electrode is fixed and arc is produced. Supplying the electric power between the electrode and the workpiece, the inlet gas from the cylinder passes through the nozzle of the welding head around the electrode. The filler metal used in this process is tungsten which has a high melting point $\left(330^{\circ} \mathrm{C}\right)$; thus, the tungsten electrode will not be melted during welding. This process is used for the welding of steel, aluminium, cast iron, magnesium, stainless steel, nickel based alloy, and copper based alloy [12]. Shaoning Geng, et al. investigated the microstructure, microhardness and corrosion behaviour in five zones from the weld metal to base metal of a 2205 duplex stainless steel joint, which was welded by double-pass tungsten inert gas arc welding with filler wire [13]. The investigation on the effects of energy density on the geometry of the weld seam and development of microstructures at various weld zones were carried out by Khan et al. [14]. Many optimisation methods are available to optimise the parameters. Among them, the Taguchi method can be applied to optimise input welding parameters. Process parameters optimisation is the key step in the Taguchi method in achieving elevated quality without escalating the cost $[15,16]$. In welding processes, the input parameters influence the mechanical properties of the welded joints. Various optimisation methods can be applied to define the desired output variables through the development of mathematical models to specify the relationship between the input parameters and output variables. One of the most powerful and widely used methods to solve this problem is the Taguchi method and it offers efficient and quality results [17]. The optimisation of welding parameters namely welding current and time in resistance spot welding of austenitic stainless steel sheets of grade AISI 316L was done by Danial Kianersi et al.[18]. Shafee et al. used the Taguchi method to improve the weld quality characteristics and reported that the ANOVA has the merit of being able to validate on a statistical basis only [19]. Many researchers have analysed the TIG welding parameters for various materials [20-24]. Lakshminarayanan et al. have done an assessment of microstructure, hardness, tensile and impact strength of friction stir welded ferritic stainless steel joints [25]. Gharibshahiyan et al. studied the effect of microstructure on hardness and toughness of low carbon welded steel using inert gas welding [26]. Arun Kumar et al. carried out multiresponse optimisation process parameters for TIG welding of Incoloy $800 \mathrm{HT}$ by Taguchi grey relational analysis [27]. Nandagopal et al. analysed the mechanical properties and optimisation of gas tungsten arc welding (GTAW) parameters on dissimilar metal titanium (6Alsingle bond4V) and aluminium 7075 by the Taguchi and ANOVA techniques [28]. Shanmugarajan et al. have optimised the laser welding parameters for welding of P92 material using Taguchi based grey relational analysis [29].

In the present work, $\mathrm{SN}$ ratio and ANOVA analysis were employed to examine the influence of the TIG welding parameters such as current (A), gas flow rate $(\mathrm{L} / \mathrm{min})$ and speed $(\mathrm{mm} / \mathrm{min})$ on the strength and hardness impact of the duplex stainless steel weld joints.

\section{Materials and testing}

\section{EXPERIMENTAL DETAILS}

The duplex stainless steel composed of $\mathrm{Fe},<0.03 \% \mathrm{C}, 21-23 \% \mathrm{Cr}, 4.5-6.5 \% \mathrm{Ni}, 2.5-3.5 \%$ Mo, $0.8-2.0 \% \mathrm{~N},<2 \% \mathrm{Mn},<1 \% \mathrm{Si},<0.03 \% \mathrm{P},<0.02 \% \mathrm{~S}$ was used as base metal. The mechanical properties of the base metal are provided in Table 1 [24]. The dimension of the base material was selected as 100X50X6 mm. Figure 1(a) shows the dimensions of the sample. The TIG welding was carried out by changing the parameters: current: 150 , 
170, $190 \mathrm{~A}$, gas flow rate:12, 14, $16 \mathrm{~L} / \mathrm{min}$, and speed: 175, 190, $210 \mathrm{~mm} / \mathrm{min}$ as shown in Table 2. The welded samples are shown in Figure 1(b). Specimens for the mechanical testing were prepared as per ASTM standards [25].

Figure 2(a) shows the impact test machine, Figure 2(b) shows the hardness test machine and Figure 2(c) shows the impact test specimens prepared as per the ASTM standard. The impact strength of the weld joints was determined using the Izord specimen. The standard Izord test specimens were prepared for the test [26]. Brinell hardness number (BHN) was obtained using a perfectly spherical hardened steel ball of $10 \mathrm{~mm}$ pressed against the test surface using a static force of $3000 \mathrm{~kg}$ for at least 10 seconds for the steel and measuring the diameters of the indentation left on the surface by means of a microscope. Brinell hardness number was calculated using the mentioned equation (1) below. This procedure was repeated for five times and an average of five readings was taken as the final Brinell hardness number. The periodical calibration of the instruments was done to determine the accuracy of the tester and to make the necessary adjustments to bring the tester within the manufacturers' tolerances.

$$
B H N=\frac{2 P}{\pi D\left(D-\sqrt{D^{2}-d^{2}}\right.}
$$

where $\mathrm{P}$, applied load ; $\mathrm{D}$, steel ball diameter in $\mathrm{mm}$; $\mathrm{d}$, depression diameter in $\mathrm{mm}$

\section{Plan of Experiments}

L27 orthogonal array was used and it consisted of three columns and 27 rows, which meant that 27 experiments were carried out. Three welding parameters with three levels were selected. The selected welding parameters for this study were: current (A), gas flow rate $(\mathrm{L} / \mathrm{min})$ and speed $(\mathrm{mm} / \mathrm{min})$. Table 2 shows the input parameters and experiment design levels. The $\mathrm{SN}$ ratio for each level of process parameters was computed based on the SN analysis. Regardless of the category of the quality characteristic, a higher SN ratio corresponded to a better quality characteristic. Therefore, the optimal level of the process parameter was the level with the highest SN ratio. Statistical software MINITAB 15 was used to analyse the experimental data. In addition, a statistical ANOVA was used for each response individually to see which process parameters had statistically major impacts on the responses. The optimal combination of the process parameters can then be predicted $[10,28-31]$.

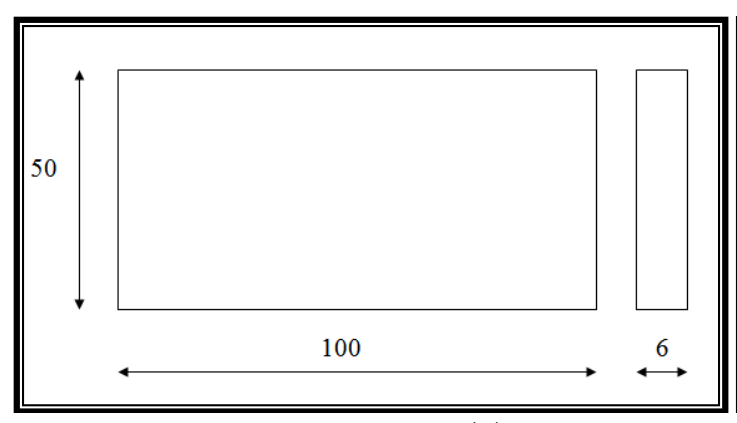

(a)

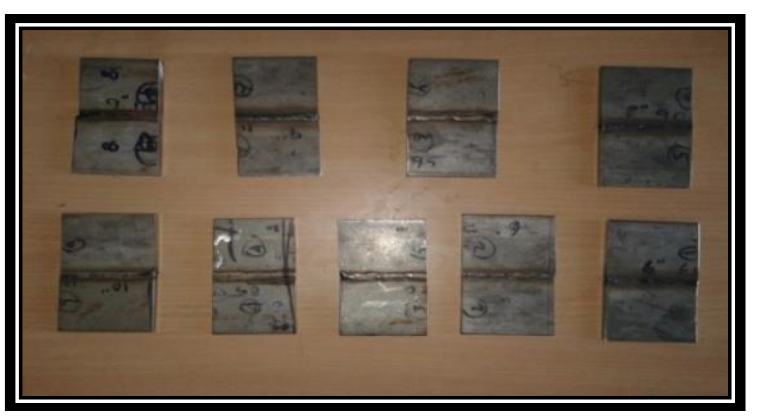

(b)

Figure 1. (a) Dimensions of the sample (all dimensions are in $\mathrm{mm}$ ) (b) TIG welded specimens. 
Table 1. Mechanical properties of 2205 grade stainless steels.

\begin{tabular}{ccccc}
\hline Grade & Tensile Strength(MPa) & Yield Strength(MPa) & Elongation (\%) & HRC \\
\hline 2205 & 621 & 448 & 25 & 31 \\
\hline
\end{tabular}

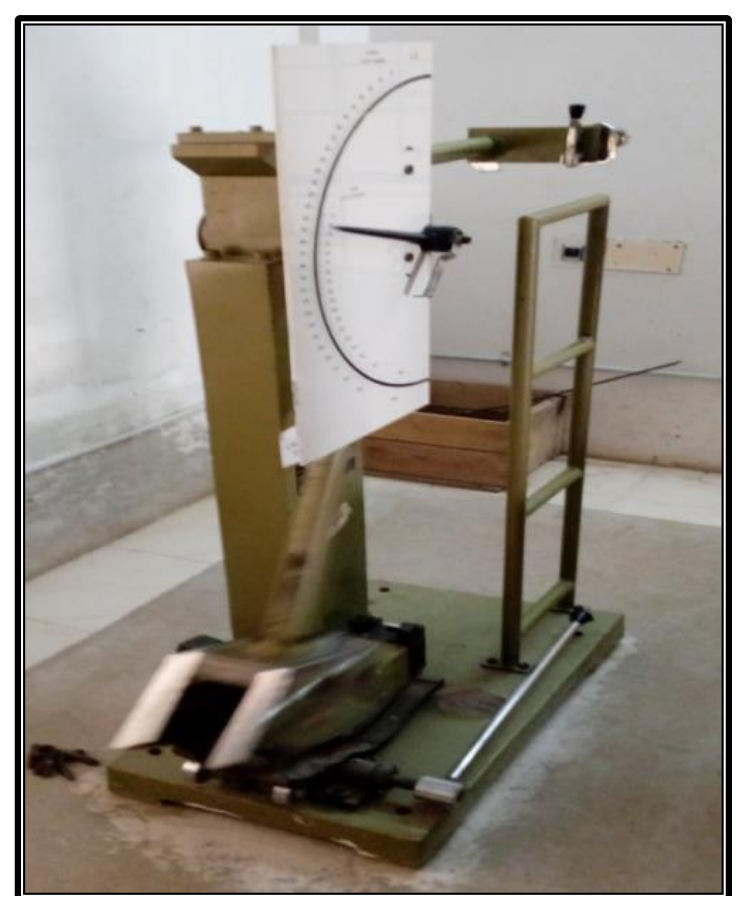

(a)

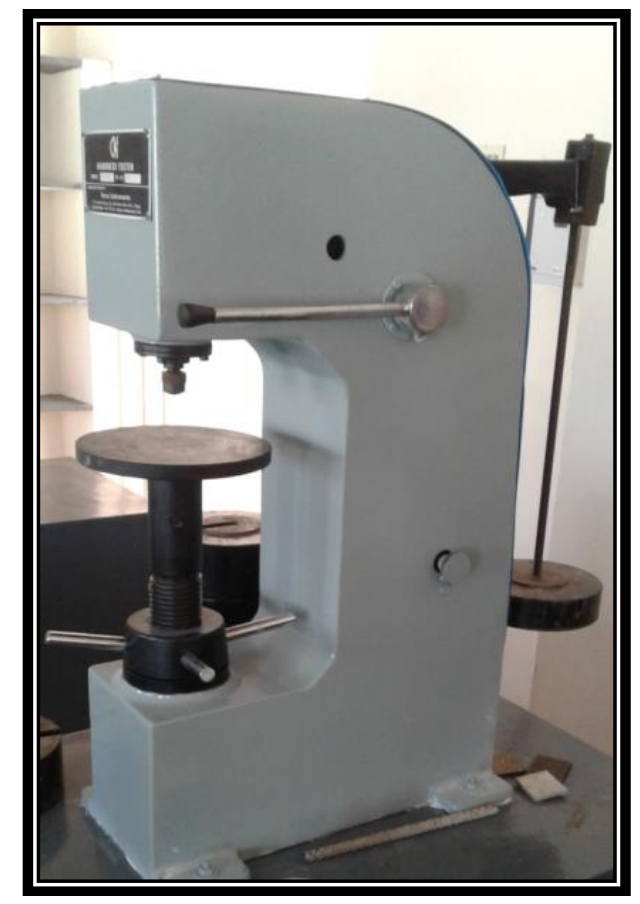

(b)

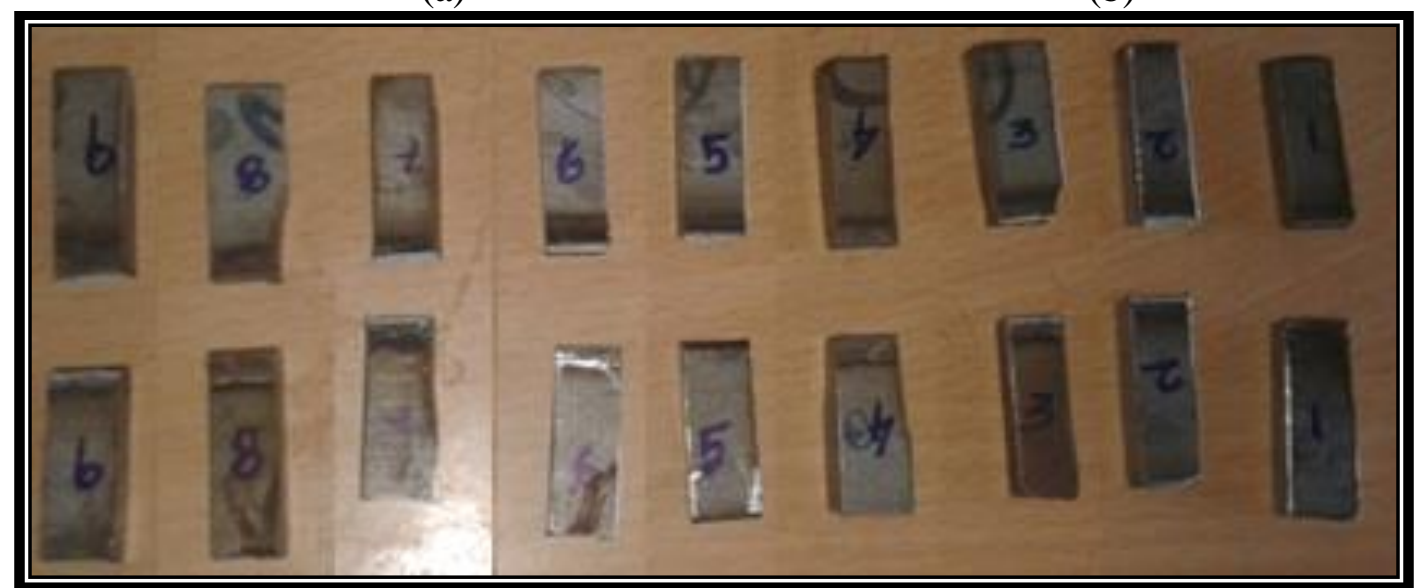

(c)

Figure 2. (a-c). Impact test machine, impact test specimens and hardness test machine.

\section{RESULTS AND DISCUSSION}

\section{SN Ratio Analysis}

The experimental layout for the process parameters using the $\mathrm{L}_{9}$ orthogonal array is shown in Table 2. To evaluate the effect of selected input factors on the output parameters, the signal-to-noise ratios and means for each factor were calculated [32-34]. The signalto-noise ratio and mean for the responses such as impact strength and hardness are presented in Table 3. The table shows the rank of the welding parameters according to the delta value. From this, the significance of the parameters was identified. For both of the responses, gas flow rate was marked as rank 1 and it was the significant factor. In this 
work, the SN ratio was selected according to the condition of 'larger is better' in order to maximise the responses. The SN ratio for the 'larger is better' target for all the responses was calculated [35] as given in Eq. (2).

$$
\text { Larger the better: } \mathrm{S} / \mathrm{N} \text { ratio }=-10 \log _{10} \frac{1}{n} \sum_{i=1}^{n} \frac{1}{y_{i}^{2}}
$$

where, $\mathrm{n}=$ number of variables; $\mathrm{y}_{\mathrm{i}}=$ the value of the response.

Table 2. Details of welding parameters.

\begin{tabular}{ccccccccc}
\hline $\begin{array}{c}\text { Experiment } \\
\text { No. }\end{array}$ & A & B & C & $\begin{array}{c}\text { Current } \\
(\text { Amps })\end{array}$ & $\begin{array}{c}\text { Gas flow } \\
\text { Rate } \\
(\text { lit/min })\end{array}$ & $\begin{array}{c}\text { Speed } \\
(\mathrm{mm} / \mathrm{min})\end{array}$ & $\begin{array}{c}\text { Impact } \\
\text { Strength } \\
(\mathrm{J})\end{array}$ & $\begin{array}{c}\text { Hardness } \\
(\text { HRB })\end{array}$ \\
\hline 1 & 1 & 1 & 1 & 150 & 12 & 175 & 1.051 & 75.66 \\
2 & 1 & 2 & 2 & 150 & 14 & 190 & 1.228 & 53.66 \\
3 & 1 & 3 & 3 & 150 & 16 & 210 & 1.028 & 54.32 \\
4 & 2 & 1 & 2 & 170 & 12 & 190 & 1.028 & 70.33 \\
5 & 2 & 2 & 3 & 170 & 14 & 210 & 1.114 & 57.00 \\
6 & 2 & 3 & 1 & 170 & 16 & 175 & 1.000 & 64.00 \\
7 & 3 & 1 & 3 & 190 & 12 & 210 & 1.114 & 70.00 \\
8 & 3 & 2 & 1 & 190 & 14 & 175 & 1.051 & 73.00 \\
9 & 3 & 3 & 2 & 190 & 16 & 190 & 1.000 & 60.66 \\
\hline
\end{tabular}

Table 3. Response table of SN ratios and means for impact strength and hardness.

\begin{tabular}{cccc}
\hline Level & Current(A) & Gas flow rate (lit/min) & Speed(rpm) \\
\hline 1 & 0.81863 & 0.53654 & 0.28804 \\
2 & 0.39252 & 1.05124 & 0.67461 \\
3 & 0.45659 & 0.07995 & 0.70509 \\
Delta & 0.42611 & 0.97129 & 0.41705 \\
Rank & 2 & 1 & 3 \\
\hline 1 & 1.102 & 1.064 & 1.034 \\
2 & 1.047 & 1.131 & 1.085 \\
3 & 1.055 & 1.009 & 1.085 \\
Delta & 0.055 & 0.122 & 0.051 \\
Rank & 2 & 1 & 3 \\
\hline 1 & 35.62 & 37.14 & 36.99 \\
2 & 36.06 & 35.66 & 35.73 \\
3 & 36.61 & 35.49 & 35.57 \\
Delta & 0.99 & 1.65 & 1.42 \\
Rank & 3 & 1 & 2 \\
\hline 1 & 61.21 & 72.00 & 70.89 \\
2 & 63.78 & 61.22 & 61.55 \\
3 & 67.89 & 59.66 & 60.44 \\
Delta & 6.67 & 12.34 & 10.45 \\
Rank & 3 & 1 & 2 \\
\hline
\end{tabular}


Figure 3 (a-b) shows the SN ratio and mean plots for the impact strength of the joints. It can be noticed from Figure 3(a) that the gas flow rate was the most important factor affecting the impact strength of the joints. Welding speed had a lower effect on the impact strength of the joints. The reason for that was welding heat input increased by increasing the welding current and by proper gas flow rate with the decreasing welding speed. Increase in welding speed will produce joints with poor microstructure properties [36]. The maximum impact strength was observed when the gas flow rate was $14 \mathrm{~L} / \mathrm{min}$, welding current was $150 \mathrm{~A}$ and the welding speed was $210 \mathrm{~mm} / \mathrm{min}$. Figure 4 shows the mean plots for the impact strength of the joints and the results were very similar to SN ratio plot. Figure 3(c) shows the SN ratio plot and Figure 3(d) shows the mean plots for the hardness of the joints. It can be understood that, from Figure 3(c), the gas flow rate was the most imperative factor affecting the hardness of the joints followed by welding speed. For any welding process using a shielding gas, the blends are important. The shielding gas is used not only to protect the molten drop and bead but also to modify metal transfer, penetration and bead width of the weld, for spatter control and post-weld cleaning, to control welding fume generation and to influence the metallurgical and mechanical properties of the weld. Shielding gas selection is therefore a determinant for welding process efficiency [37]. The maximum hardness was observed when the gas flow rate was $12 \mathrm{~L} / \mathrm{min}$, welding current was $190 \mathrm{~A}$ and the welding speed was $170 \mathrm{~mm} / \mathrm{min}$. Figure 3(d) shows the mean of mean plots for the hardness of the joints and the results were very similar to the results observed for $\mathrm{SN}$ ratio plot of hardness.

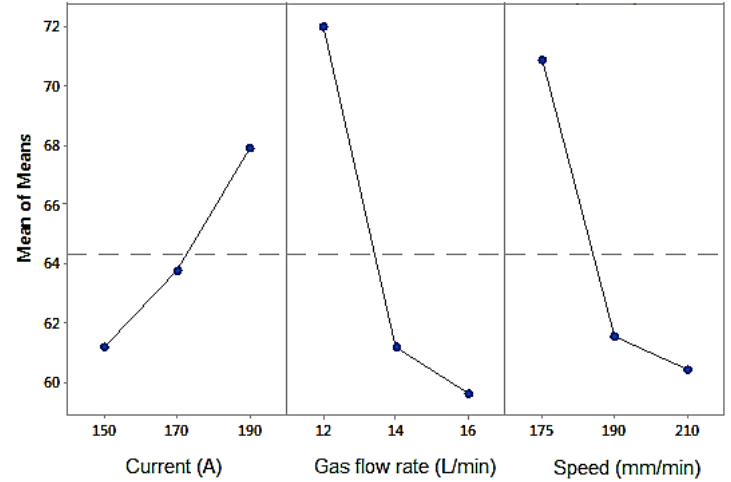

(a)

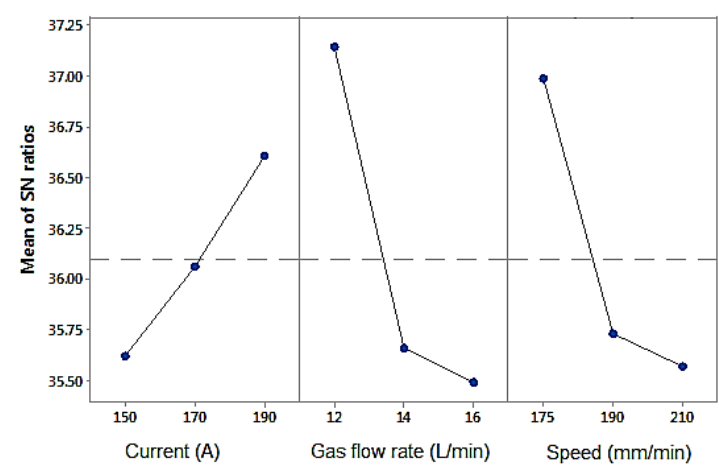

(c)

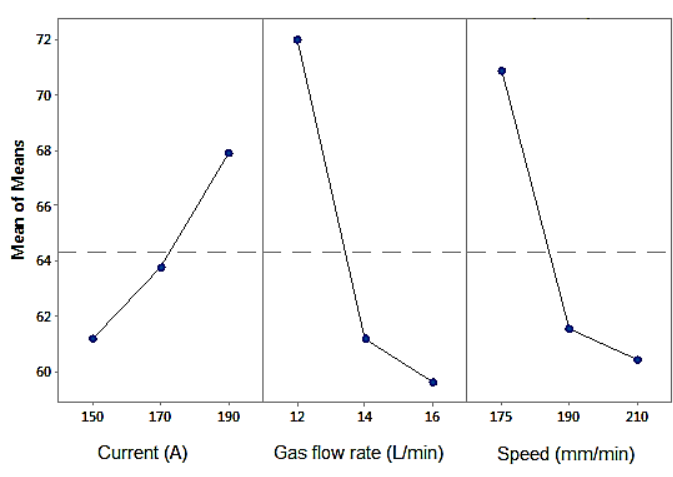

(b)

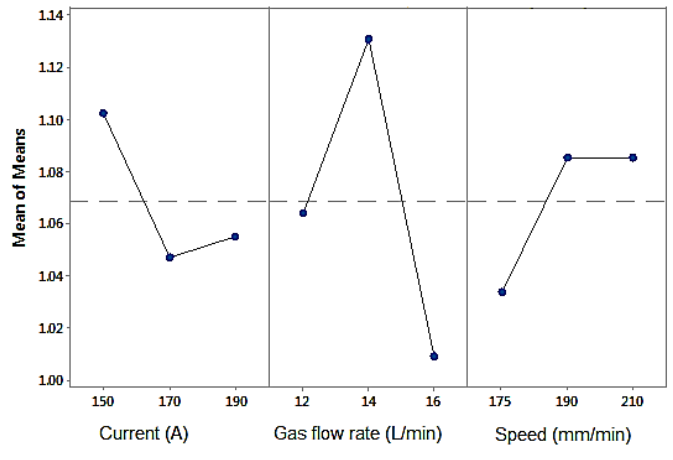

(d)

Figure 3. Main effect of plot of (a) mean of SN ratios for impact strength (b) mean of means for impact strength (c) mean of SN ratios for hardness, (d) mean of means for hardness. 


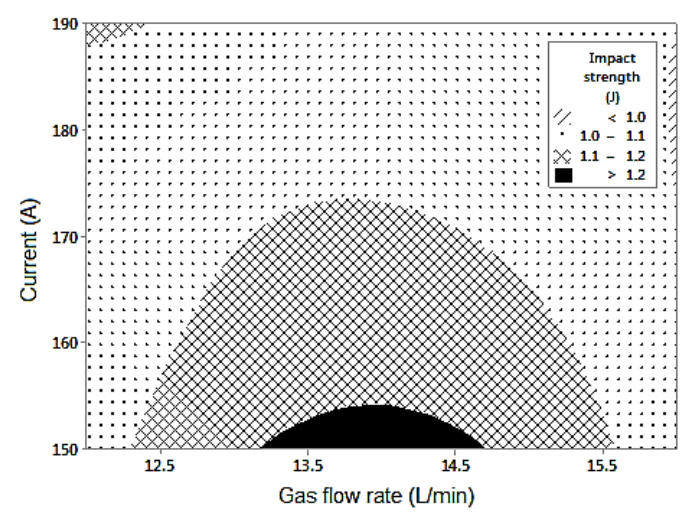

(a)

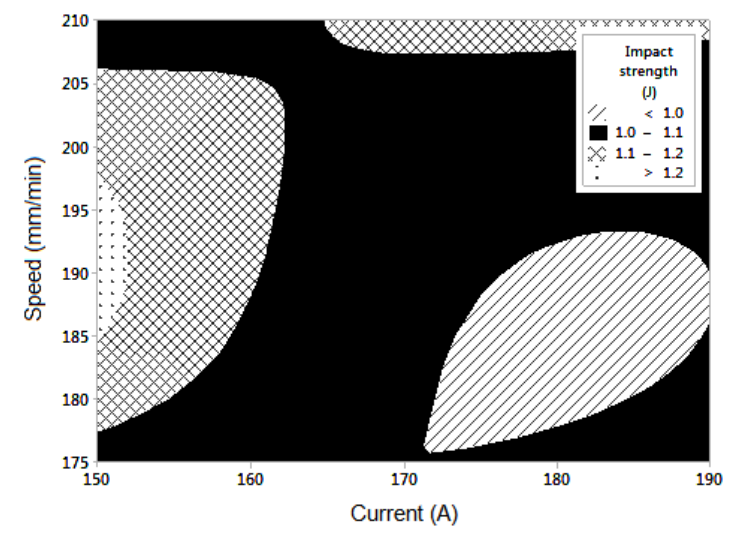

(c)

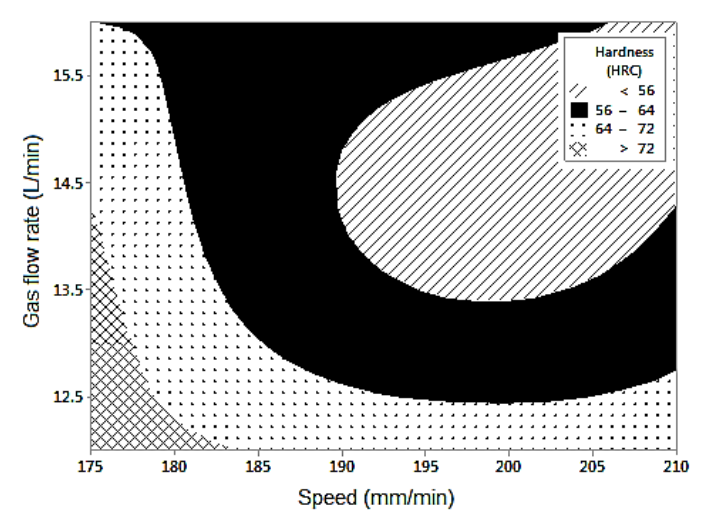

(e)

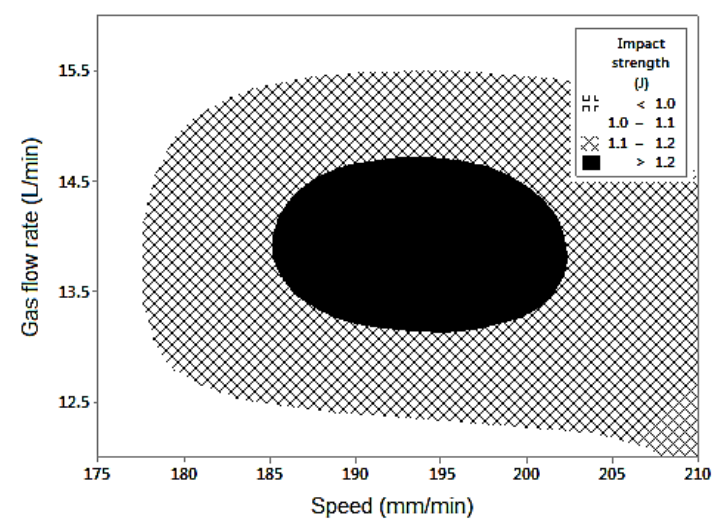

(b)

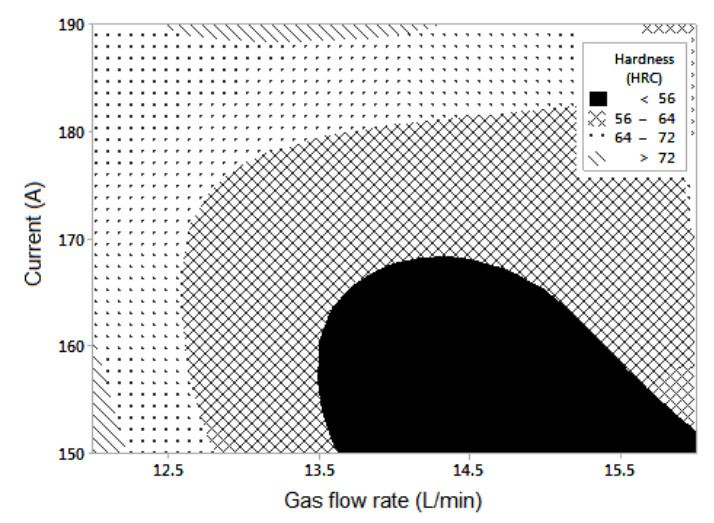

(d)

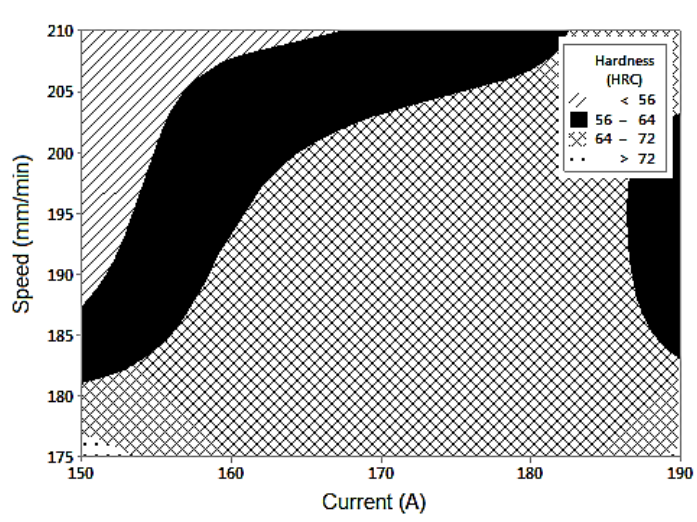

(f)

Figure 4. Contour plot for (a-c) impact strength and (d-f) hardness

\section{Contour Analysis}

Contour plot shows the details of impact strength with welding current versus gas flow rate, welding speed versus gas flow rate and current versus welding speed. From Figure 4(a), it was observed that the maximum value of impact strength was obtained for the low welding current and when the gas flow rate was between the 13.5 and $1.5 \mathrm{~L} / \mathrm{min}$. In Figure 4(a), the dotted region shows the poor impact strength of the joints which meant that high current during welding was not advisable. Generally, high current produces high temperature and by which more melting of materials is occurred [38]. After cooling the molten base materials, the brittleness was improved and it enhanced the hardness of the 
joints. Figure 4(b) shows the contour plot of impact strength drawn between gas flow rate and welding speed. The highest impact strength was observed when the gas flow rate was $14.5 \mathrm{~L} / \mathrm{min}$ and the welding speed was $195 \mathrm{~mm} / \mathrm{min}$. The low impact strength was observed when the welding speed and gas flow rate were low. Figure 4(c) shows the contour plot of impact strength for the welding peed versus welding current. The impact strength was high for the welding speed of $197 \mathrm{~mm} / \mathrm{min}$ and the welding current of 150 A. The low impact strength was observed when the welding current was high and welding speed was low. The reason for that was the high welding current will lead to the high melting of base material and poor microstructure in welding region during solidification

Figure 4(e-f) shows the contour plot for hardness with respect to the parameters such as welding current, gas flow rate and welding speed. From Figure 4(d), the high hardness was obtained for the joints welded at high current and moderate gas flow rate conditions. The high current always produces the joints with high hardness because of overheating and cooling to room temperature [39]. Low gas flow rate and low welding speed were the ideal conditions for producing TIG welding duplex stainless steel joints with high hardness as shown in Figure 4(e). When considering the welding current and welding speed for producing the TIG welding joint with high hardness, it was very essential to maintain low welding current and low welding speed as shown in Figure 4(f).

\section{ANOVA Analysis of Welding Parameters}

Welding process parameters can be investigated by ANOVA to verify the parameters that significantly affected the quality characteristic. Additionally, the F test was used to analyse the welding parameters on the significant effect of the output parameters. Generally, the change of the any process parameter has a significant effect on the quality characteristic when the F value is large [32]. Table 4 shows the results of ANOVA for the impact strength of the joints. The high $\mathrm{F}$ value indicated that the factor was highly significant in affecting the response of the any process. Hurlbert reported in his study that researchers provide the degrees of freedom, the F-value and the p-value. But unfortunately, many people only look at the p-value whilst overlooking the degrees of freedom and the F-value. This is dangerous, because if the degrees of freedom are not correct, the F-value and the p-value are practically meaningless [40]. In this study, gas flow rate was a highly significant factor in affecting the impact strength of the TIG welded duplex stainless steel joints followed by welding current and welding speed.

Table 4. ANOVA for impact strength and hardness of the joints.

\begin{tabular}{lccccc}
\hline Source & DF & Adj SS & Adj MS & F-Value & P-Value \\
\hline Current (A) & 2 & 0.005324 & 0.002662 & 0.53 & 0.652 \\
Gas flow rate (lit/min) & 2 & 0.022272 & 0.011136 & 2.23 & 0.310 \\
Speed (rpm) & 2 & 0.005270 & 0.002635 & 0.53 & 0.655 \\
Error & 2 & 0.009991 & 0.004995 & & \\
Total & 8 & 0.042858 & & & \\
\hline \multicolumn{5}{c}{ S=0.0706785; R-sq=76.69\%; R-sq(adj)=6.75\%; R-sq(pred):0\% } \\
\hline Current (A) & 2 & 68.00 & 33.998 & 4.06 & 0.197 \\
Gas flow rate (lit/min) & 2 & 270.76 & 135.382 & 16.18 & 0.058 \\
Speed (rpm) & 2 & 197.54 & 98.769 & 11.81 & 0.078 \\
Error & 2 & 16.73 & 8.366 & & \\
Total & 8 & 553.03 & & & \\
\hline \multicolumn{6}{c}{ S=2.89237; R-sq=96.97\%; R-sq(adj)=87.90\%; R-sq(pred):38.73\% } \\
\hline
\end{tabular}


Table 4 shows the results of ANOVA for the hardness of the TIG welded joints. The gas flow rate was a highly significant factor in affecting the hardness of the TIG welded duplex stainless steel joints followed by welding speed [30]. In this case, welding current was the insignificant factor to affect the hardness of the joints. The Regression Equation was developed to predict the impact strength and hardness of the joints with the welding parameters and the developed equations were given in equations (3) \& (4). Regression analysis was used to find equations that fit the data. Once the regression equation was obtained, the model can be used to make predictions. One type of regression analysis is linear analysis [41].

Impact strength

$$
\begin{aligned}
& \mathrm{J}=1.0682+0.0341 \mathrm{~A}_{1}-0.0209 \mathrm{~A}_{2}-0.0132 \mathrm{~A}_{3}-0.0039 \mathrm{~B}_{1} \\
& +0.0628 \mathrm{~B}_{2}-0.0589 \mathrm{~B}_{3}-0.0342 \mathrm{C}_{1}+0.0171 \mathrm{C}_{2}+0.0171
\end{aligned}
$$

Hardness

$$
\begin{aligned}
& \mathrm{HRB}=64.292-3.08 \mathrm{~A}_{1}-0.52 \mathrm{~A}_{2}+3.59 \mathrm{~A}_{3}+7.70 \mathrm{~B}_{1} \\
& -3.07 \mathrm{~B}_{2}-4.63 \mathrm{~B}_{3}+6.59 \mathrm{C}_{1}-2.74 \mathrm{C}_{2}-3.85 \mathrm{C}_{3}
\end{aligned}
$$


Figure 5.SEM images (a) top surface of base metal at higher magnification (b) top surface at lower magnification (c) welded at $\mathrm{A}_{1} \mathrm{~B}_{2} \mathrm{C}_{3}$ conditions (d) welded at $\mathrm{A}_{2} \mathrm{~B}_{1} \mathrm{C}_{2}$ conditions.

\section{SEM Analysis}

Figure 5 (a-b) shows the SEM image of the top surface on the base metal of duplex stainless steel 2205. Figure 5(c) and (d) shows the SEM image of the top surface on the weldment of duplex stainless steel 2205 joints welded at $\mathrm{A}_{1} \mathrm{~B}_{2} \mathrm{C}_{3}$ and $\mathrm{A}_{2} \mathrm{~B}_{1} \mathrm{C}_{2}$ conditions. From Figure 5(a) and (b), it was clear that the reason why the duplex stainless steel was called duplex was because it had a two phase microstructure consisting of grains of ferritic and austenitic stainless steel [42]. The austenitic phase was presented as islands surrounded by the ferritic phase [43], but the dendrite structure was observed for the weldment region as shown in Figure 5(c-d). These structures are usually observed when 
the molten metal freezes and the shape is produced by faster growth along energetically favourable crystallographic directions. A dendrite in metallurgy is a tree-like structure of crystals or others growing as molten metal freezes, and the energetically favourable crystallographic directions are the shapes produced by the faster growth. This dendritic growth has huge consequences in regard to material properties [44]. These structures are observed because of the melting and solidification of duplex stainless steel from the liquid phase to a completely ferritic structure $[45,46]$. These structures are good in order to have high mechanical properties of the joints.

\section{CONCLUSIONS}

Tungsten Inert Gas welding parameters were studied for duplex stainless steel (2205) using SN ratio and ANOVA analysis. Welding current, gas flow rate and welding speed were considered as the welding parameters and impact strength and hardness were taken as responses. From the $\mathrm{SN}$ ratio analysis, it was concluded that high impact strength can be obtained when the welding current was $150 \mathrm{~A}$, gas flow rate was $14 \mathrm{~L} / \mathrm{min}$ and the welding speed was $210 \mathrm{~mm} / \mathrm{min}$. Also, the high hardness of the joints could be obtained when the welding current was $190 \mathrm{~A}$, gas flow rate was $12 \mathrm{~L} / \mathrm{min}$ and the welding speed was $175 \mathrm{~mm} / \mathrm{min}$. SEM images for base metal and the welded zone of welded joints were reported. The dendrite structure was observed in the weldment region. ANOVA analysis indicated that the gas flow rate was the most significant parameter for both impact strength and hardness of the joints.

\section{ACKNOWLEDGEMENTS}

The authors gratefully acknowledge the support provided by the Chendhuran College of Engineering and Technology, Pudukkottai, India for providing the Laboratory facility to complete this work successfully.

\section{REFERENCES}

[1] Qi S, Jian W, Li H-b, Yue L, Hu Y-d, BAI J-g, et al. Chi Phase after Short-term Aging and Corrosion Behavior in 2205 Duplex Stainless Steel. Journal of Iron and Steel Research, International. 2016;23:1071-9.

[2] Haque MM, Limon SA, Moniruzzaman M, Bepari MM. Corrosion comparison of galvanized steel and aluminum in aqueous environments. International Journal of Automotive and Mechanical Engineering. 2014;9:1758.

[3] Brytan Z, Niagaj J. Corrosion studies using potentiodynamic and EIS electrochemical techniques of welded lean duplex stainless steel UNS S82441. Applied Surface Science. 2016;388:160-8.

[4] Sathiya P, Jaleel MA, Katherasan D, Shanmugarajan B. Optimization of laser butt welding parameters with multiple performance characteristics. Optics \& Laser Technology. 2011;43:660-73.

[5] Hatifi M, Firdaus M, Razlan A. Modal analysis of dissimilar plate metal joining with different thicknesses using MIG welding. International Journal of Automotive and Mechanical Engineering. 2014;9:1723-33.

[6] Shah LH, Mohamad UK, Yaakob KI, Razali AR, Ishak M. Lap joint dissimilar welding of aluminium AA6061 and galvanized iron using TIG welding. Journal of Mechanical Engineering and Sciences. 2016;10:1817-26. 
[7] Hasan MM, Ishak M, Rejab MRM. A simplified design of clamping system and fixtures for friction stir welding of aluminium alloys. Journal of Mechanical Engineering and Sciences. 2015;9:1628-39.

[8] Ishak M, Noordin NFM, Razali ASK, Shah LHA, Romlay FRM. Effect of filler on weld metal structure of AA6061 aluminum alloy by tungsten inert gas welding. International Journal of Automotive and Mechanical Engineering. 2015;11:243846.

[9] Chaki S, Ghosal S. A GA-ANN hybrid model for prediction and optimization of $\mathrm{CO}_{2}$ laser-mig hybrid welding process. International Journal of Automotive and Mechanical Engineering. 2015;11:2458-70.

[10] Kumar A, Sundarrajan S. Effect of welding parameters on mechanical properties and optimization of pulsed TIG welding of Al-Mg-Si alloy. The International Journal of Advanced Manufacturing Technology. 2009;42:118-25.

[11] Shah L, Akhtar Z, Ishak M. Investigation of aluminum-stainless steel dissimilar weld quality using different filler metals. International Journal of Automotive and Mechanical Engineering. 2013;8:1121.

[12] Juang S, Tarng Y. Process parameter selection for optimizing the weld pool geometry in the tungsten inert gas welding of stainless steel. Journal of Materials Processing Technology. 2002;122:33-7.

[13] Geng S, Sun J, Guo L, Wang H. Evolution of microstructure and corrosion behavior in 2205 duplex stainless steel GTA-welding joint. Journal of Manufacturing Processes. 2015;19:32-7.

[14] Khan M, Romoli L, Ishak R, Fiaschi M, Dini G, De Sanctis M. Experimental investigation on seam geometry, microstructure evolution and microhardness profile of laser welded martensitic stainless steels. Optics \& Laser Technology. 2012;44:1611-9.

[15] Anawa E, Olabi A-G. Using Taguchi method to optimize welding pool of dissimilar laser-welded components. Optics \& Laser Technology. 2008;40:37988.

[16] Sadeghi SH, Moosavi V, Karami A, Behnia N. Soil erosion assessment and prioritization of affecting factors at plot scale using the Taguchi method. Journal of Hydrology. 2012;448:174-80.

[17] Pan LK, Wang CC, Hsiao YC, Ho KC. Optimization of Nd: YAG laser welding onto magnesium alloy via Taguchi analysis. Optics \& Laser Technology. 2005;37:33-42.

[18] Kianersi D, Mostafaei A, Amadeh AA. Resistance spot welding joints of AISI 316L austenitic stainless steel sheets: Phase transformations, mechanical properties and microstructure characterizations. Materials \& Design. 2014;61:251-63.

[19] Shafee S, Naik BB, Sammaiah K. Resistance spot weld quality characteristics improvement by Taguchi method. Materials Today: Proceedings. 2015;2:2595604.

[20] Ragavendran M, Chandrasekhar N, Ravikumar R, Saxena R, Vasudevan M, Bhaduri A. Optimization of hybrid laser-TIG welding of 316LN steel using response surface methodology (RSM). Optics and Lasers in Engineering. 2017;94:27-36.

[21] Huang B, Zhang J, Wu Q. Microstructure and mechanical properties of China low activation martensitic steel joint by TIG multi-pass welding with a new filler wire. Journal of Nuclear Materials. 2017;490:115-24. 
[22] Zhang Y, Wang H, Chen K, Li S. Comparison of laser and TIG welding of laminated electrical steels. Journal of Materials Processing Technology. 2017;247:55-63.

[23] Ye Z, Huang J, Gao W, Zhang Y, Cheng Z, Chen S, et al. Microstructure and mechanical properties of 5052 aluminum alloy/mild steel butt joint achieved by MIG-TIG double-sided arc welding-brazing. Materials \& Design. 2017;123:6979.

[24] Raabe D. New developments in stainless steels-impacts from markets and technology. Steel Research International. 2008;79:403.

[25] Lakshminarayanan A, Balasubramanian V. An assessment of microstructure, hardness, tensile and impact strength of friction stir welded ferritic stainless steel joints. Materials \& Design. 2010;31:4592-600.

[26] Gharibshahiyan E, Raouf AH, Parvin N, Rahimian M. The effect of microstructure on hardness and toughness of low carbon welded steel using inert gas welding. Materials \& Design. 2011;32:2042-8.

[27] Srirangan AK, Paulraj S. Multi-response optimization of process parameters for TIG welding of Incoloy $800 \mathrm{HT}$ by Taguchi grey relational analysis. Engineering Science and Technology, an International Journal. 2016;19:811-7.

[28] Nandagopal K, Kailasanathan C. Analysis of mechanical properties and optimization of gas tungsten Arc welding (GTAW) parameters on dissimilar metal titanium $(6 \mathrm{Al} 4 \mathrm{~V})$ and aluminium 7075 by Taguchi and ANOVA techniques. Journal of Alloys and Compounds. 2016;682:503-16.

[29] Shanmugarajan B, Shrivastava R, Sathiya P, Buvanashekaran G. Optimisation of laser welding parameters for welding of P92 material using Taguchi based grey relational analysis. Defence Technology. 2016;12:343-50.

[30] Kadirgama K, Noor M, Rahman M. Optimization of surface roughness in end milling using potential support vector machine. Arabian Journal for Science and Engineering. 2012:1-7.

[31] Kadirgama K, Noor M, Rahman M, Rejab M, Haron CHC, Abou-El-Hossein KA. Surface roughness prediction model of 6061-T6 aluminium alloy machining using statistical method. European Journal of Scientific Research.2009; 25(2):250-56.

[32] Hong K-M, Shin YC. Prospects of laser welding technology in the automotive industry: A review. Journal of Materials Processing Technology. 2017;245:46-69.

[33] Oliveira J, Miranda R, Fernandes FB. Welding and Joining of NiTi Shape Memory Alloys: A Review. Progress in Materials Science. 2017.

[34] Abou-El-Hossein K, Kadirgama K, Hamdi M, Benyounis K. Prediction of cutting force in end-milling operation of modified AISI P20 tool steel. Journal of Materials Processing Technology. 2007;182:241-7.

[35] Canel T, Kaya AU, Celik B. Parameter optimization of nanosecond laser for microdrilling on PVC by Taguchi method. Optics \& Laser Technology. 2012;44:2347-53.

[36] Ghazvinloo H, Honarbakhsh-Raouf A, Shadfar N. Effect of arc voltage, welding current and welding speed on fatigue life, impact energy and bead penetration of AA6061 joints produced by robotic MIG welding. Indian Journal of Science and Technology. 2010;3:156-62.

[37] Mvola B, Kah P. Effects of shielding gas control: welded joint properties in GMAW process optimization. The International Journal of Advanced Manufacturing Technology. 2017;88:2369-87. 
[38] Oluwole OI, Ajibade OJ. Effect of welding current and voltage on the mechanical properties of wrought (6063) aluminium alloy. Materials Research. 2010;13:1258.

[39] Ravichandran M, Anandakrishnan V. Optimization of powder metallurgy parameters to attain maximum strength coefficient in $\mathrm{Al}-10$ wt\% $\mathrm{MoO} 3$ composite. Journal of materials research. 2015;30:2380-7.

[40] Hurlbert SH. Pseudoreplication and the design of ecological field experiments. Ecological monographs. 1984;54:187-211.

[41] Rajakumar S, Muralidharan C, Balasubramanian V. Predicting tensile strength, hardness and corrosion rate of friction stir welded AA6061-T 6 aluminium alloy joints. Materials \& Design. 2011;32:2878-90.

[42] Sudhakaran R, Sivasakthivel P, Nagaraja S, Eazhil K. The effect of welding process parameters on pitting corrosion and microstructure of chromiummanganese stainless steel gas tungsten arc welded plates. Procedia Engineering. 2014;97:790-9.

[43] Moharana BR, Sahu SK, Sahoo SK, Bathe R. Experimental investigation on mechanical and microstructural properties of AISI 304 to $\mathrm{Cu}$ joints by $\mathrm{CO} 2$ laser. Engineering Science and Technology, an International Journal. 2016;19:684-90.

[44] Britto Joseph G, Mageshwaran G, Kona Rajesh JJ. Study and analysis of welding of dissimilar metals 409 stainless steel and 439 stainless steel by TIG welding.

[45] Vitek J, Dasgupta A, David S. Microstructural modification of austenitic stainless steels by rapid solidification. Metallurgical Transactions A. 1983;14:1833-41.

[46] Charde N. Microstructure and fatigue properties of dissimilar spot welded joints of AISI 304 and AISI 1008. International Journal of Automotive and Mechanical Engineering. 2013;7:882-90. 